THÉMATA. Revista de Filosofía

$\mathrm{N}^{\circ} 51$, Enero-junio (2015) pp.: 125-143

ISSN: 0212-8365 e-ISSN: 2253-900X

doi: 10.12795/themata.2015.i51.07

\title{
CAPITAL HUMANO Y VOLUNTAD DE PODER ${ }^{1}$
}

\author{
HUMAN CAPITAL AND WILL TO POWER
}

Cristián De Bravo Delorme ${ }^{2}$

CONICYT, Chile - Universidad de Sevilla

Recibido: 28-04-2014

Aceptado: 29-06-2014

\begin{abstract}
Resumen: El presente artículo propone una interpretación ontológica del concepto de capital humano a la luz de la metafísica de Nietzsche y de "El Trabajador" de Jünger. En ese sentido cabe preguntarse por el fundamento y las implicancias de aquel concepto que habiendo crecido dentro del ámbito económico, supone sin embargo el suelo de una nueva comprensibilidad de la posición histórica del hombre.
\end{abstract}

Palabras-clave: Nihilismo, Capital, Poder, Inversión, Trabajador.

\begin{abstract}
The following paper proposes an ontological interpretation of the concept of human capital in light of Nietzsche's Metaphysics and Jünger's "The Worker". In this way one might wonder about the basis and the implications of that concept that having grown up in the economic field, it supposes however the ground of a new comprehension about the historical position of man.
\end{abstract}

Key-words: Nihilism, Capital, Power, Investment, Worker.

[1] Este trabajo forma parte del proyecto de investigación postdoctoral, Becas Chile, CONICYT.

[2] (cdebravo@us.es) Doctor en Filosofía por la Universidad de Chile. Investigador postdoctoral en el Departamento de Estética e Historia de la Filosofía, Facultad de Filosofía, Universidad de Sevilla. Miembro del Centro de Estudios Heideggerianos. Miembro comité editorial de la revista internacional de estudios sobre Heidegger y pensamiento contemporáneo Differenz, Universidad de Sevilla. "La doxa. Traducción del $§ 15$ de Conceptos fundamental de la filosofía aristotélica de M. Heidegger". Revista Áperion, 2015. Estudios de Filosofía [Abril]. 2014 "Aristóteles, Ética a Nicómaco, libro II (1103a 14-1109b 29)" Traducción fenomenológica con introducción y notas. Revista Ápeiron. Estudios de Filosofía, n 1, Octubre, Madrid. 2014 "El sentido de la poiesis en el Banquete de Platón. Una contribución al problema de la esencia de la técnica". Revista Alpha, n 38, Julio, Osorno, Chile. 2013 "El fenómeno 'histérico' en Grecia y el Cristianismo". Gaceta de Psiquiatría Universitaria (GPU), Año 9 , Vol. 9, n 4, Diciembre, Santiago, Chile. 2013 "Sentido de la imaginación en William Wordsworth". Revista Ideas y Valores, volumen LXII, n 153, Diciembre, Bogotá, Colombia. 


\section{Introducción}

La democratización global de las costumbres, las cuales se han venido desarrollando a través del libre negocio y el comercio, han contribuido en gran medida a que las naciones se hayan podido abrir unas a otras a través de un intercambio incesante de experiencias y proyectos. Además, los progresivos logros tecnológicos que determinan el dominio creciente del saber científico, no sólo entregan cada vez nuevos recursos para la eficaz administración de las cosas, sino que además posibilitan situaciones insospechadas, las cuales, sabiéndolas manejar, pueden abrir caminos esperanzadores para la actual humanidad. En todas partes se advierte vida y movimiento, decisiones autónomas y acuerdos plurales, creación individual y gestiones colectivas, y si acaso aparecen circunstancias críticas o posiciones de resistencia ante el actual estado de cosas, nunca se descubren del todo insurgentes como para cuestionar la feliz meta que la razón ha venido dictando desde hace ya largo tiempo. En efecto, ya sea llegando al extremo en las acciones o se esté ubicado sensatamente en el centro, cualquiera sea el caso, cada uno discute y lucha por el hombre y para el hombre.

Bajo otra perspectiva, sin embargo, todo este ajetreo constante de las tareas cotidianas no parece ser más que el disfraz de un estacionamiento. Más aún, la sociedad actual parece estar suspendida en un vacío, para cuyo fingimiento sólo cabe concentrar las fuerzas en la organización de todo ${ }^{3}$. En ese sentido la organización material que un aparato estatal dispone ante los padecimientos y urgencias de los hombres, llámese a esta organización sistema de salud o seguridad social, no haría otra cosa que narcotizar el dolor de este vacío. De ninguna manera se declara un punto de vista pesimista con la constatación de tal fenómeno, cuyo estado patológico Nietzsche entendió como debilidad y agotamiento de la fuerza espiritual. Para decirlo con mayor claridad, el descubrimiento de esta situación es el supuesto fundamental que nos puede orientar para esclarecer los "síntomas" de la enfermedad, si vale nombrar como enfermedad a la situación de nuestro tiempo4. Por lo tanto, la "anormalidad" y el "extrañamiento" como "síntomas" sólo podrán comprenderse, de acuerdo a Foucault, como consecuencias "de las contradicciones sociales en las que el hombre está históricamente alienado» ${ }^{5}$.

[3] Cf. Heidegger, M. Überwindung der Metaphysik en Vorträge und Aufsätze, Gesamtausgabe Band 7, Vittorio Klostermann, 2000, pág. 94ss. Además en un trabajo anterior se ha hecho referencia a un camino para conectar la esencia de la técnica moderna y su origen platónico-griego. Cf.

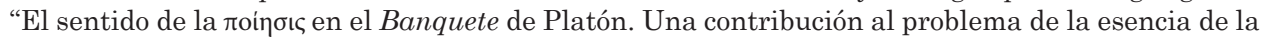
técnica" en revista Alpha, №38, Julio, 2014, págs. 227-242.

[4] Cf. Jünger, E. "Sobre la Línea" en Acerca del nihilismo. Ediciones paidós I.C.E/U.A.B, 1994, pág. 31ss.

[5] Foucault, M. Enfermedad mental y personalidad. Editorial Paidos, Barcelona, 1984, pág. 116.

THÉMATA. Revista de Filosofía, Nº51 enero-junio (2015) pp.: 125-143

doi: 10.12795/themata.2015.i51.07 
Bajo este enfoque quisiera plantear la pregunta por este vacío que trata de llenarse con la creciente organización del Mundo, lo cual, a su vez, afecta de manera destacada al pensamiento y al ánimo filosófico. En lo que sigue me orientaré por un fenómeno particular del presente, pero que, como sugeriré, tiene la tendencia a tener un carácter total. Trataré de hacer una serie de indicaciones que nos permitan avistar qué es lo que se encuentra en juego al proponer una relación entre un concepto surgido dentro del ámbito económico, a saber, el Capital humano, y aquella expresión que Nietzsche acuña para determinar la esencia de la vida. Lo que quisiera mostrar es que aquel concepto económico que configura el sentido del trabajador actual con creciente extensión se arraiga precisamente en el suelo metafísico del pensamiento de Nietzsche. Esto no quiere decir, sin embargo, que este fenómeno económico sea una necesaria consecuencia del pensamiento de aquel. Para desde ya hacer una advertencia respecto al enfoque hermenéutico que me orienta, no tiene sentido apelar aquí a una interpretación objetiva de un determinado pensador. Esto vale sobre todo para la interpretación que Heidegger hace de Nietzsche y en la cual bajo una determinada perspectiva tomo parte. Pues es verdad que la voluntad de poder, así como el concepto de superhombre y el eterno retorno, no implican necesariamente la vinculación con el dominio planetario, la subjetividad incondicionada y la vuelta consistente de lo presente, tal como, según se dice ${ }^{6}$, parece incurrir la interpretación heideggeriana. Lo que a mi juicio, sin embargo, vale en la interpretación de Nietzsche y a su vez en la interpretación de Ernst Jünger que aquí yo quisiera intentar, es, de acuerdo a las palabras de Pedro Cerezo, "la potencia pensante para afrontar la facticidad histórica" Pues en cuanto confrontación con la fuerza de las cosas, todo pensamiento filosófico puede transformarse y recrearse conforme a su ambigüedad intrínseca, la cual no es ningún defecto, sino la necesaria derivación de su riqueza. Lo importante, según esto, no es tanto la "objetividad" de la interpretación como la capacidad de arraigar al suelo histórico, nuestro suelo, el pensamiento filosófico de un pensador, para que nos sirva de orientación más vinculante con el acontecer del Mundo.

\section{El Capital humano como concepto económico}

Quisiera partir indicando un fenómeno que ha ido tomando injerencia paulatinamente en el Mundo y en cierto modo ha estado operando en proporción al creciente proceso de racionalización que ya Max Weber había mencionado como un carácter determinante de la época moderna. Haré mención, por

[6] Cf. Löwith, K. "Heidegger, pensador de un tiempo indigente. Sobre la posición de la filosofía en el siglo XX”, Fondo de cultura económica, México, 2006, pág. 307ss.

[7] Cerezo, P. "La cuestión del Nihilismo. La confrontación Nietzsche/Heidegger" en Pensar la Nada. L. Sáez, J. de la Higuera y J. F. Zúñiga (Eds). Biblioteca Nueva Madrid, 2007, pág. 246.

THÉMATA. Revista de Filosofía, No51 enero-junio (2015) pp.: 125-143 doi: 10.12795/themata.2015.151.07 
lo pronto, a un hecho actual que indica hacia lo que quiero plantear y que tiene que ver con una determinada gestión gubernamental que es, a mi juicio, un signo del actual estado del Mundo. Tal gestión, por otra parte, sirve como una de las pocas instancias para encontrar un "punto de resistencia" que el orden de cosas concede como parte de su operación simuladora, la cual, en este caso, es llevada a cabo a través de la empresa del conocimiento. Exige una atención importante, porque afecta de lleno al autor de estas palabras, la política de un determinado ministerio de educación al crear, por ejemplo, un programa de becas llamado "Formación de capital humano avanzado". Lo importante que se consigna aquí bajo el nombre de Capital humano y la relación que se establece con un programa de becas de un ministerio de un país exige a mi juicio una reflexión de amplio alcance. Pero acaso no resulte del todo insólito para muchos que la educación de las personas permanezca ligada a la política económica de un país y que, por tanto, la inversión que un Estado hace en una persona implique una retribución y una ganancia conjunta, para un investigador y para una nación. No es algo accidental, por lo demás, que Foucault en su curso $\mathrm{Na}$ cimiento de la biopolítica haya hecho mención a este fenómeno surgido específicamente dentro del contexto de la formación de un nuevo modo de gobierno y de una nueva política económica. Ahí Foucault hace una expresa indicación a las implicancias del desplazamiento de una interpretación del Capital, cuyo sentido, bajo el marco del neoliberalismo económico norteamericano, sólo estaba dado por los bienes y la acumulación de dinero. En 1959 Theodore Schultz, teórico del Capital humano, señalaba la inminencia de que el hombre se considerara como el más propio Capital, pues sólo a partir del modo de sobrepotenciar las propias capacidades intelectuales y los niveles de habilidad de la vida trabajadora, sólo a partir de su renovada gestión, es decir, a partir de la inversión de los propios recursos por medio de una instrucción educacional, sería posible una más óptima administración de los recursos dentro la movilización de todas las fuerzas productivas. Por consiguiente, se afirma que una progresiva adquisición de conocimiento asegura para la vida en el futuro su satisfacción individual y bienestar. En suma, asegura la riqueza de una nación. Schultz reconoce en primer lugar que el hombre es el Capital. Veamos más de cerca esto.

En un nivel económico resulta, literalmente, que el hombre, en cuanto fácticamente obligado a relaciones de Mercado, en tanto cotidianamente participa del negocio y del servicio, y esto no de manera accidental, sino bajo una determinada disposición gubernamental que Foucault claramente ha descrito, ha llegado a ser el Capital por antonomasia. Schultz se sorprendía de que aun no se hubiese reconocido esto:

«¿Por qué somos tan reluctantes en reconocer cuál es el papel de la riqueza humana? La mera idea de hacerlo parece ofendernos; discutirlo abiertamente parece hacer que muchas personas se sientan humilladas. ¿Por qué es visto como algo de mal gusto? La respuesta es

THÉMATA. Revista de Filosofía, No 51 enero-junio (2015) pp.: 125-143 doi: 10.12795/themata.2015.i51.07 
porque no podemos fácilmente pasar por encima de nuestros valores y creencias; estamos fuertemente inhibidos de mirar a los hombres como una inversión, excepto en la esclavitud, y eso nosotros lo abominamos. Tampoco es bueno para nuestra concepción ver al hombre mirarse a sí mismo como una inversión, eso también puede resultarnos degradante. Nuestras instituciones políticas y legales han sido moldeadas para mantener al hombre libre de la esclavitud. (...) Es por eso que es comprensible entender por qué el estudio del hombre, cuando se trata a sí mismo como si fuera riqueza, va contra valores profundamente arraigados, porque podría parecer que lo reduce una vez más a un componente material, a algo semejante a la propiedad, y eso estaría equivocado. Ante todo, el hombre libre es el objeto a ser servido. Nada menos que J. S. Mill insistía que los habitantes de una nación no deben ser vistos como riqueza porque la riqueza existe sólo por y para los habitantes. Pero ciertamente Mill estaba equivocado, porque no hay nada en el concepto de riqueza humana que implique que ella no puede existir totalmente en beneficio de los habitantes (...) Lo que es difícil de explicar, sin embargo, es que los economistas modernos hayan descuidado por tanto tiempo la inversión en el hombre?

Schultz admite algo que en Marx era supuesto ontológico fundamental. Marx dice al inicio de su obra El Capital:

«La riqueza de las sociedades en las que domina el modo de producción capitalista se presenta como un enorme cúmulo de mercancías, y la mercancía individual como la forma elemental de la riqueza ${ }^{9} \gg$

Esto significa, siguiendo a Martínez Marzoa ${ }^{10}$, que, bajo el horizonte del Mundo interpretado como sociedad capitalista y, por lo tanto, bajo las determinadas relaciones y medios de producción a partir del Capital, la riqueza es lo que una sociedad tiene como lo más propio, es decir, es lo que realmente hay en una sociedad, en suma, lo entitativamente ente del Mundo, y en ese sentido lo ente como mercancía tiene un determinado modo de ser cuya constitución esencial se determina a partir de su valor, es decir, a partir de la estimación por la cual la vida humana pone al ente en movimiento. La mercancía en cuanto mercancía es cuando tiene valor medible y sólo así puede constituir riqueza. Y ¿en dónde la mercancía tiene su fuente de valor y, por lo tanto, la medida de su ser? Del trabajo o, más precisamente, de la fuerza de trabajo y del tiempo calculable y medible de ese esfuerzo. De acuerdo a ello, el hombre en tanto trabajador o, mejor dicho, en cuanto vende su fuerza de trabajo, tiene el carácter de mercancía a partir del valor cuantificable, según los conceptos de Marx. En cuanto a lo que dice Marx sólo eso es importante para nuestra reflexión.

Pues bien, Schultz da cuenta que el sentido común podría sentirse ofendido al proponer al hombre como capaz de ser invertido como si fuese propiedad de otro, como valor de cambio, dado que ello implicaría considerarlo

[8] Schultz, Th. "Investment in man: an economist view", The Social Service Review. Vol. XXXIII, N. 2. 1959, Pág.10.

[9] Marx K. El Capital, libro primero, crítica de la economía política, el proceso de producción de capital, Siglo veintiuno editores, 2008, pág. 43.

[10] Martínez Marzoa, F. "La filosofía de «El Capital» de Marx”, Taurus ediciones, 1983, pág. 33.

THÉMATA. Revista de Filosofía, Nº51 enero-junio (2015) pp.: 125-143

doi: 10.12795/themata.2015.i51.07 
como mercancía, lo cual va contra toda dignidad. Sin embargo, en la medida que Schultz permanece orientado por la interpretación del ser como valor, necesariamente ha de ver la más propia riqueza en el hombre como el Capital. La esencia del valor, bajo la perspectiva de Schultz, no surge de la relación diferenciada entre Capital y fuerza de trabajo que puede conllevar el usufructo y la alienación, sino del Capital interpretado como la fuente misma de la riqueza, es decir, como el propio ser del hombre. Es precisamente el ser como Capital, en términos económicos: el haber nacido en un buen entorno familiar, el haber sido bien educado y el haber establecido determinadas relaciones sociales; en suma, el haberse capacitado para producir más valor a partir de sí mismo, lo que constituye la base de toda riqueza humana y social. Por tanto Schultz transforma la contraposición entre Capital y fuerza de trabajo convirtiendo a todo hombre no en mercancía, pues eso es el temor del sentido común, sino en Capital, específicamente en Capital humano. ¿Qué se esconde tras esta constatación de Schultz? Consideremos bajo un primer nivel de análisis de dónde puede nacer esta evidencia.

\section{El Capital humano como consecuencia de la tecnificación de la vida}

El carácter de nuestro tiempo se expresa a partir del extensivo imperio de una determinada razón instrumental que conlleva la planificación y administración social de lo ente ya interpretado en su disponibilidad. Esta capacidad de ordenación racional, según ya lo declara Descartes ${ }^{11}$, se funda en el proyecto de dominar a la naturaleza y, ulteriormente, en el emplazamiento técnico de sus elementos de acuerdo a los objetivos de la empresa social. Ramón Queraltó considera que en la medida que el proyecto de dominio técnico de la naturaleza constituye esencialmente un poder transformador, la vida humana se encuentra determinada, en forma cada vez creciente, por una racionalidad técnica, es decir, una racionalidad que dispone de los medios a la vista de un fin ya dado. En los términos de la Física moderna esa operación racional no radica meramente en una desinteresada objetivación de las cosas, sino esencialmente en la disposición y el sometimiento creciente de lo ente. En términos fácticos esta racionalidad se lleva a cabo a través de un determinado cálculo de medios con arreglo a un fin, lo cual implica en esencia el mismo proceder con el cual opera la Física. En uno y otro caso, en el modo como la Física calcula y mide lo ente para de esta manera dominarlo y reproducirlo, y en el modo como la vida fáctica opera racionalmente en el Mundo como Mercado, se da lo mismo, a saber, una racionalidad técnica. La operación consiste en medir y calcular las circunstancias y los medios para conseguir un fin ya dado y así repetirlo progresivamente, en el caso del trabajador, a la vista de la acumulación de riqueza.

[11] Cf. Descartes, R. Discurso del Método, Biblioteca Edaf, 2005, pág. 93.

THÉMATA. Revista de Filosofía, No51 enero-junio (2015) pp.: 125-143 doi: 10.12795/themata.2015.i51.07 
La racionalidad técnica, bajo la exigencia del ser como Capital, reclama por eso totalidad, pues

«si la dimensión constitutiva de la acción técnica es la eficacia operativa, entonces un mayor grado de eficacia se alcanzará conforme se vayan ampliando sucesivamente los límites de la realidad susceptibles de racionalización técnica. Así, que cada vez deba existir más tecnología, y que cada vez se extienda más la razón técnica como forma de acceso a lo real, son dos consecuencias lógicamente derivadas de la naturaleza misma de la racionalidad técnica» ${ }^{12}$.

La capitalización que constituye la esencia de la tecnología conlleva que este determinado logos organice la sociedad según el criterio de la eficacia operativa, con lo cual se pone en evidencia que el comportamiento y las relaciones sociales tiendan cada vez más a orientarse por esta específica racionalidad. En la medida que este tipo de racionalidad técnica se extiende

«va adquiriendo al mismo tiempo una suerte de ascendiente moral, imponiéndose a la par como criterio de validación y legitimación, tomando el relevo de las ideologías en su múltiple función: orientadora de las conductas, elemento de cohesión y estratificación social» ${ }^{13}$.

Este tipo de racionalidad técnica, cuya lógica instrumental orienta los comportamientos, es precisamente la racionalidad dominante de la Economía, desde la cual se eleva a una nueva forma el trabajador, cuyos recursos en su creciente sobreacumulación se encuentran invertidos por el cálculo técnico y la medida racional capitalizadora.

Esto se puede ver claramente en el modo como la teoría económica comprende el Capital humano, pues supone una racionalidad técnica maximizadora, en la medida que el trabajador para acumular su propio Capital debe tener en cuenta las tasas social y privada de retorno de las inversiones, analizando todo a partir de la rentabilidad económica futura. Por ello al interpretar el ser de la vida trabajadora como Capital las relaciones sociales no pueden sino tender a orientarse a partir de este tipo de racionalidad en todo orden de cosas, comparando los beneficios y costos de tal o cual elección de amistades, de educación e incluso de matrimonio. Bajo este nivel de análisis, cuando la vida trabajadora se configura a partir de la administración de los propios recursos como una «unidad-empresa»" ${ }^{14}$, conlleva por lo pronto en menor o mayor grado los siguientes fenómenos: conducta estratégica de la persona, uso eficaz de la capacidad y diversificación de servicios para el crecimiento con el fin de lograr una mayor rentabilidad. En ese sentido, si

[12] Queraltó, R. "Razón científica y razón técnica en el fin de la modernidad", Anuario Filosófico, 1994 (27), pág. 688.

[13] García de la Huerta, M. Crítica de la razón tecnocrática, Editorial Universitaria, Chile, 1990, pág. 43.

[14] Foucault, M. Nacimiento de la biopolítica, Fondo de cultura económica, Buenos Aires, 2007, pág. 264.

THÉMATA. Revista de Filosofía, No51 enero-junio (2015) pp.: 125-143

doi: 10.12795/themata.2015.i51.07 
la vida es interpretada a partir de su propia idoneidad para el trabajo rentable, es decir, si el hombre se encuentra emplazado bajo esta determinada vocación a producir y reproducir renta acumulativamente a partir de sus propios recursos, entonces él mismo tiene que llegar a ser necesariamente una inversión y en primer lugar del Estado. Pues desde el momento en que el hombre toma parte en la sociedad y, por tanto, tan pronto comienza a educarse como ciudadano del Mundo interpretado a partir del Mercado, su ser es interpretado como Capital. En ese sentido los recursos y habilidades de cada Capital deben ser administrados para el incremento de la productividad y, así, de la rentabilidad, incluso en aquellas actividades como la Filosofía que parecían resistirse a tal exigencia ${ }^{15}$.

Para ejemplificar de una manera vinculante el sentido del Capital humano quisiera detenerme un momento en cómo esta nueva forma del trabajo afecta al ejercicio filosófico. Pues el ejercicio filosófico actual no se encuentra excusado de ejercer su posibilidad dentro del espacio de juego del Mercado. Incluso puede que quien ejerza la Filosofía decida toda su gestión y actividad de manera calculada en favor de una voluntad de empresa. El mencionado programa de inversión conocido en Chile como "Formación de capital humano avanzado", la venta del servicio académico en la Universidad, la instalación de un patrón investigativo y la imposición institucional de un tipo de discurso a través del paper ${ }^{16}$, por ejemplo, son cuatro aspectos que contribuyen a determinar un tipo de ejercicio filosófico orientado por la metodología de las ciencias naturales y motivado a la producción y administración de la empresa individual y político-cultural. Pero la Filosofía no se vuelve cuestionable por el sólo hecho de participar del negocio y porque de hecho corresponda a ciertas demandas que, a juicio del más romántico, podrían ir en contra de su propia esencia, sino porque entre estas exigencias del Mundo del Mercado y la propia posibilidad de la Filosofía pareciera suprimirse la distancia que ésta exige para sí misma con respecto a las cosas. Esta distancia crítica le permite al ejercicio filosófico poder sostenerse como lo que es, a saber, como un modo de estar despierto ante las cosas, a cuyo encuentro se entrega la voluntad general. Sin este espacio crítico el ejercicio filosófico puede dislocarse y someterse así al puro rendimiento que el Mundo económico impone. La Filosofía al responder a la exigencia de su profesionalización ${ }^{17}$, en último término, puede corresponder a

[15] Santos Herzeg, J. "Filosofía de mercado. El filósofo profesional como MINY-PYME" en Paralaje $\mathrm{N}^{\circ}$ 7, Dossier, 2011, pág. 49ss.

[16] Cf. Santos Herzeg, J. "Tiranía del Paper. Imposición institucional de un tipo discursivo" en Revista chilena de literatura, Noviembre, N82, 2012a, pp. 197-217; Santos Herzeg, J. "30 años de filosofía-FONDECYT. Construcción de una elite e instalación de una patrón investigativo" en La Cañada $\mathrm{N}^{\circ} 3,2012 b$, pp. 76-116.

[17] Respecto al carácter del profesional y específicamente del profesional de la filosofía cf. Santos Herzeg, J. "El trabajo filosófico en la época de la profesionalización" en La presencia de la filosofía en la Universidad, Porto Alegre, 2003, págs. 145-159.

THÉMATA. Revista de Filosofía, No51 enero-junio (2015) pp.: 125-143 doi: 10.12795/themata.2015.i51.07 
la autoproducción técnica de los propios recursos, cuya finalidad reside en el incremento de la rentabilidad. Esta rentabilidad al que todo profesional, incluido el que ejerce la Filosofía, se encuentra forzado, obtiene su derecho y sentido en el todo de las relaciones significativas del Mundo interpretado a partir del Mercado. Así incluso la refugiada posibilidad filosófica se encuentra en peligro de ceder a los requerimientos del Mundo, a pesar de su aparente entereza y su autoencomiada independencia.

Debemos advertir entonces que el ejercicio filosófico respectivo, conforme a la tendencia creciente de interpretar el ser como Capital, puede ser secuestrado por las exigencias del negocio. Incluso el más extremista y reaccionario debe de algún modo ejercer su interpretación de la Filosofía y de las cosas bajo este tipo de relaciones económicas y ello no en perjuicio de él, sino precisamente en su provecho, dado que sólo correspondiendo a la exigencia de acumulación de Capital, en este caso concentrado en el curriculum, puede el profesional de la Filosofía conquistar una posición frente a los otros y un rango. En la medida que la Filosofía es una posibilidad humana que se ejerce fácticamente, ella misma se encuentra forzada y siempre en riesgo de ser arrastrada por las posibilidades del Mundo. Pero esto implica que no sólo puede perder su propiedad, sino además enredarse en una posibilidad que si bien es fácil justificar ante la opinión común, no deja de inquietar a quien la ejerce. Aparentemente la Filosofía actual si quiere ejercer su posibilidad sólo puede hacerlo desapropiándose, por así decir, y precisamente sabiéndose desapropiada, a saber, como Capital humano. Por ello ante todo debemos nosotros mismos sentirnos interpelados en la interpretación del Capital humano, en este instante de la historia del Mundo en que el conocimiento determina a la sociedad actual, una sociedad que de acuerdo al progreso de la ciencia ha puesto el valor supremo del Capital en la vida humana.

En lo siguiente quisiera resaltar y dar algunas indicaciones hacia aquella dimensión más amplia desde la cual toma forma el Capital humano bajo una voluntad de conocer como principio de un orden de cosas que probablemente abarque mucho tiempo. La perspectiva que tomo me lleva a interpretar el Capital humano, en tanto cumplimiento de la Forma del Trabajador, como el principio de la voluntad de poder dentro del Nihilismo como el proceso planetario en el cual nos encontramos.

\section{La Forma del Trabajador en la historia como Nihilismo}

Las reflexiones anteriores no han dado aún con la esencia del problema. Más bien lo que allí se ha ofrecido no es sino la expresión en superficie de aquel fenómeno que Nietzsche comprendió bajo la imagen del «más inquietante de todos los huéspedes» ${ }^{18}$. Hace un momento afirmé dogmáticamente algo, a saber,

[18] Nietzsche, F. Fragmentos póstumos IV, Tecnos, Madrid, 2006, pág. 114.

THÉMATA. Revista de Filosofía, No 51 enero-junio (2015) pp.: 125-143 doi: 10.12795/themata.2015.i51.07 
que el Capital humano se presenta como principio de la voluntad de poder. Por tanto quisiera explicarme planteando la posibilidad de pensar el concepto de Capital de manera metafísica y en toda su amplitud. Tenemos que tomar por ello un nuevo punto de partida.

Quisiera volver a comenzar tomando algunas indicaciones de El Trabajador de Ernst Jünger. Este texto fue escrito entre el fin de la primera guerra mundial y el comienzo de la segunda, por lo tanto, en el vórtice de decisiones históricas. Jünger nombra al Trabajo como «la expresión de un ser especial que intenta llenar su espacio propio, henchir su tiempo propio, cumplir sus leyes propias ${ }^{19}$. Estas palabras están dichas conforme a un esencial proyecto por el cual se debe hacer visible algo que ya está ahí, pero que aún no se ha cobrado conciencia de ello. Sin embargo, lo que Jünger quiere poner a la vista se encuentra iluminado por una previa configuración de la mirada. El proyecto de $E l$ Trabajador está escrito a la luz de la metafísica de Nietzsche y en ese sentido el Trabajador es quien lleva a cumplimiento activo la superación del Nihilismo. Así puede decir Jünger que «se ha vuelto inútil seguir ocupándose en una transvalorización de todos los valores -ahora basta con ver las cosas nuevas y participar de ellas» ${ }^{20}$.

Preguntamos entonces ¿de dónde obtiene su derecho el Trabajo para que el Mundo mismo se plenifique de sentido a partir de su Forma? Para ello debemos concentrarnos en el acontecimiento esencial del Nihilismo a partir de la metafísica de Nietzsche. Nietszche experimenta el Nihilismo como el acontecimiento por el cual «los valores supremos se desvalorizan» ${ }^{21}$. El Nihilismo es el proceso a través del cual los valores válidos hasta el momento pierden su fuerza vinculante, implicando «el descenso y retroceso del poder del espíritu» ${ }^{22}$. Los valores platónico-cristianos, los valores puestos por la moral del hombre occidental y que le habían dado sentido al Mundo, sus ideales, aspiraciones y metas ahora se vuelven nihil, esto es, vanos y vacíos. El Nihilismo es el acontecimiento histórico por el cual la verdad de lo ente se transforma, pues el dominio de lo suprasensible se derrumba al punto de que la historia misma se revela como la historia del enmascaramiento de este proceso de anonadamiento. En el punto extremo irrumpe la pregunta por la finalidad de todo. Una cita bastará para comprender este proceso enmascarador de desvalorización de los valores:

«La pregunta del nihilismo: «ipara qué?» parte del hábito tenido hasta el momento en virtud del cual la meta parecía puesta, dada, exigida desde fuera - por alguna autoridad sobrehumana. Después de que se ha desaprendido a creer en ésta, se busca sin embar-

[19] Jünger, E. El Trabajador. Dominio y figura, Tusquets editores, Barcelona, pág. 90.

[20] Ibidem, pág. 58.

[21] Nietzsche, F. Fragmentos póstumos IV, ed. cit., pág. 241.

[22] Ibidem, pág. 242.

THÉMATA. Revista de Filosofía, Nº51 enero-junio (2015) pp.: 125-143 doi: 10.12795/themata.2015.i51.07 
go, siguiendo el viejo hábito, OTRA autoridad que sepa hablar incondicionadamente, que pueda ordenar metas y tareas. La autoridad de la CONCIENCIA pasa ahora a primer plano (cuanto más emancipada de la teología, más imperativa se vuelve la moral); como compensación de una autoridad personal. O la autoridad de la RAZÓN. O el instinto social (el rebaño). O la historia con un espíritu inmanente, que tiene su meta en sí misma y a la que uno se puede entregar. Se desearía eludir la voluntad, el querer una meta, el riesgo de darse a sí mismo una meta; se desearía abandonar la responsabilidad (- se aceptaría el fatalismo) Finalmente: la felicidad, y, con un poco de hipocresía, la felicidad de la mayoría (...) Precisamente ahora, cuando sería necesaria la voluntad con su mayor fuerza, está en su punto más débil y más pusilánime. Absoluta desconfianza en la fuerza organizadora de la voluntad para la totalidad ${ }^{23}$,

Estas palabras son importantes porque dan cuenta de un momento esencial del Nihilismo. Pues en el punto extremo del Nihilismo, en su acabamiento, en donde el Nihilismo es un «estado NORMAL» ${ }^{24}$, se libera la posibilidad de una nueva posición de valores y, por lo tanto, se revela el auténtico principio de una transvaloración de todos los valores. Este principio en el acabamiento del Nihilismo se trata de evitar, se le teme, pero su aparición es irresistible. Nietzsche se refiere a que precisamente en el momento de la mayor necesidad de fuerza creadora de valores persiste el debilitamiento. Al momento crítico, sin embargo, Nietzsche lo nombra como Nihilismo activo, a saber, el «signo del acrecentado poder del espíritu» ${ }^{25}$. Este poder del espíritu es voluntad de poder, la cual nombra la esencia misma de la vida. En cuanto principio de la nueva posición de valores es «la fuerza organizadora de la voluntad para la totalidad». Por tanto, la transvaloración de todos los valores significa que esta fuerza organizadora, la voluntad de poder, es el contramovimiento al movimiento del Nihilismo pasivo, al debilitamiento y al empobrecimiento de la vida. Respecto a esta contraposición Nietzsche afirma:

«El empequeñecimiento del hombre debe valer durante largo tiempo como única meta: porque hay que crear una base amplia para que una especie más fuerte de hombre pueda erigirse sobre ella: como hasta ahora toda especie más fuerte se ha erigido sobre un nivel inferior» ${ }^{26}$.

La superación del Nihilismo, de acuerdo a lo anterior, supone el empequeñecimiento total del hombre, pues sólo de este modo puede liberarse la voluntad de poder como fuerza creadora de nuevos valores. En ese sentido su irrupción es la animación de la vida organizadora que puede llevar a cabo desde sí misma esa transvaloración. Es aquí precisamente donde Jünger avista la posibilidad de una nueva realidad, donde "la anarquía se asemeja a la confusión propia de esas noches abundantes de sueños en las que el espíritu se alza

[23] Ibidem, pág. 244.

[24] Ibidem, pág. 241.

[25] Ibidem, pág. 242.

[26] Ibidem, pág. 239.

THÉMATA. Revista de Filosofía, Nº51 enero-junio (2015) pp.: 125-143

doi: 10.12795/themata.2015.i51.07 
pertrechado de fuerzas nuevas para órdenes nuevos» ${ }^{27}$. Estas fuerzas se elevan a partir de la Forma del Trabajador como aquella «especie más fuerte». Jünger ve en el Trabajador la Forma de la humanidad que puede asumir la tarea de transvalorar todos los valores habidos hasta el momento conforme al poder único de la voluntad de poder. En suma, ve en el Trabajador el único Tipo humano capaz de ser «el sentido de la Tierra» ${ }^{28}$.

El Trabajador como aquel que lleva a cabo el Nihilismo activo, según Jünger, se contrapone a los valores del burgués, pero de tal manera que su esencia sobrepasa el ámbito económico desde el cual había surgido a partir de la conceptualidad burguesa. Los valores del Trabajador que habían sido determinados por la vida burguesa, se contraponen de manera esencial a los valores del burgués como valores ya derrumbados, de tal modo que puede Jünger interpretar tácitamente la contraposición de Nietzsche entre Dionisos y Cristo bajo la Forma del Trabajador y el burgués. Dejo abierto sin embargo aquí qué sentido tiene tal contraposición al nombrar Nietzsche al Superhombre como «Cesar romano con alma de Cristo» ${ }^{29}$. Por ahora se trata de ver cómo la esencia del Trabajador se hace patente y de dónde viene la exigencia vinculante de su ser. Jünger se refiere a la liberación del Trabajador de las ataduras de los valores anteriores y la necesidad de vincularse a otra libertad en la que el Trabajador se desligue del Mundo económico. Pero tal cosa no significa rehusar ese Mundo, sino ponerlo bajo un nueva Forma bajo la orden de un nuevo sentido. «Significa que el eje de la sublevación no es ni la libertad económica, ni el poder económico, sino el poder en sír» ${ }^{30}$. Sólo de esta manera «la Forma del Trabajador posee una validez planetaria» ${ }^{31}$. Así la verdad del Trabajador depende de la legitimidad de su poder, esto es, de la aseguración del punto de vista de la vida. El Trabajador es la determinación del animal indeterminado y lo puesto en esta determinación es su Forma.

Precisemos con mayor rigor. Donde la vida humana está puesta en juego, ahí tiene que alcanzar desde sí, para sí y sobre sí su conformación y, por tanto, su Forma. La esencia del Trabajador, desde la óptica de Jünger, se mide así a partir de su Forma, la cual permanece en reposo por sobre el acontecer, pero no trascendentalmente, al modo platónico-cristiano, sino que es puesta a la vista, creada por la vida misma. Para Jünger se hace patente «una voluntad de conformación que intenta captar la vida en su totalidad y ponerla en Forma» ${ }^{32}$. Para Nietzsche conocer es esquematizar, imponer regularidad al Caos, fijar lo

[27] Jünger, E. Op. Cit. pág. 62.

[28] Nietzsche, F. Así habló Zaratustra, Alianza editorial, Madrid, 1996, pág. 34.

[29] Nietzsche, F. Fragmentos póstumos III, Tecnos, Madrid, 2010, pág. 628.

[30] Jünger, E. Op. Cit. Pág. 35-36.

[31] Ibidem, pág. 257. Modifico la traducción de figura por Forma.

[32] Ibidem. Pág. 201.

THÉMATA. Revista de Filosofía, Nº51 enero-junio (2015) pp.: 125-143 doi: 10.12795/themata.2015.i51.07 
que «fluye y se mueve, cuyo orden está oculto y cuya ley no conocemos de inmediato» ${ }^{33}$. La fijación de la Forma esencial, su verdad vinculante, proviene de la necesidad práctica de la vida misma, de su voluntad de estabilizarse, de asegurarse a sí misma esquematizando la insurgencia del acontecer. La voluntad de poder da forma al ente, no ya transcendentalmente, como Dios, como Conciencia, como Razón, como Historia teleológica, como Felicidad individual e incluso universal. La voluntad de poder enmascarada en la trascendencia exige ahora una vinculación incondicionada, porque «la suprema voluntad de poder es imprimir el carácter de ser al devenir» ${ }^{34}$. Jünger ve la necesidad que la vida creadora al tener a la vista «ese mar de fuerzas que en sí mismas se desencadenan y suben como una marea» deba arrojarse "como portadora de una voluntad de poder completamente determinada que posee una especificidad propia y unos objetivos propios» ${ }^{35}$. Sólo que Jünger no entiende la voluntad de poder suficientemente, pues puede decir que «la pura voluntad de poder no posee legitimación, como tampoco la posee la voluntad de fe ${ }^{36}$. Pero el poder es un signo de existencia, por tanto «los medios reciben su significado del poder que se sirve de ellos» ${ }^{37}$. Ello significa que el poder se legitima a sí mismo cuando quien lo tiene es poseído por él y así poseso comprende los medios de su propia legitimación. El dominio, más expresamente, el "señorío del Mundo» ${ }^{38}$, dice Jünger, es "una legitimación revolucionaria - esto es: una representación de la Forma del Trabajador por aquellos medios con los que esta Forma moviliza el Mundo» ${ }^{39}$.

La legitimación del poder se funda en la representación de la Forma, es decir, en el poner la vida en Forma y disponer el Mundo a partir del determinado Tipo acuñado por la Forma. El Tipo es ese Tipo de humanidad que se alza del empequeñecimiento conjunto y asume su libertad como obligación total de una raza, en la cual la acuñación de la Forma del Trabajador alcanza su Tipo más claro. Siendo el rendimiento en el cual se expresa la totalidad del Trabajo lo único que decide en su espacio, y siendo encarnado este rendimiento por unos símbolos objetivos y fácticos, sólo al Tipo del Trabajador le es encomendada la tarea de reconocerlos e interpretarlos como los medios para movilizar totalmente materia y hombres. Es el Tipo el único que participa y se alimenta de la fuente de donación de sentido de la Forma. Es el único que sabe interpretar la Técnica como el símbolo supremo de la Forma del Trabajador y como el medio por el cual la Forma del Trabajador moviliza la totalidad de los recursos, es decir, el Mundo

[33] Heidegger, M. Nietzsche I, Ediciones Destino, Barcelona, 2000, pág. 454.

[34] Nietzsche, F. Fragmentos póstumos IV, ed. cit., pág. 221.

[35] Jünger, E. Op. Cit. Pág. 72.

[36] Ibidem. Pág. 73.

[37] Idem.

[38] Ibidem. Pág. 145.

[39] Ibidem. Pág. 251.

THÉMATA. Revista de Filosofía, Nº51 enero-junio (2015) pp.: 125-143 doi: 10.12795/themata.2015.i51.07 
totalmente disponible por la vida creadora de nuevos valores para su propio aseguramiento y plenitud. El Trabajo aparece así como la realidad de todo lo real en la época del Trabajador. En este sentido puede decir Heidegger que «la completa organización técnica del Mundo es ya el fundamento metafísico para todos los planes y operaciones, y [...] este fundamento es experimentado incondicional y radicalmente, y llevado a su consumación en el Trabajo» ${ }^{40}$.

\section{El Capital humano como consumación de la Forma del Trabajador}

En este punto tenemos que preguntar si efectivamente el nuevo Tipo de Trabajador toma la Forma del Capital humano. Jünger dice expresamente y no de manera accidental, que el ser del Trabajador «es poder en un sentido completamente diferente», ese ser, dice, "es un Capital original que se invierte tanto en el Estado como en el Mundo y que se forja a sí mismo sus propias organizaciones y sus propios conceptos» ${ }^{41}$. Jünger utiliza la palabra Capital en sentido metafísico y aludiendo incluso al carácter de inversión del Capital. Sin embargo, inversión quiere decir aquí sacrificio, es decir, el acto por el cual la vida se entrega y sirve. Jünger dice: «donde el ser humano despliega su fuerza suprema, donde despliega dominio, es en todos aquellos sitios donde sirve» ${ }^{42}$, pues "la más honda felicidad del ser humano consiste en ser sacrificado»" Por tanto, la frase: el ser del Trabajador es un Capital original que se invierte tanto en el Estado como en el Mundo quiere decir que el poder esencial del Trabajador, que proviene de la Forma de su representación, debe entregarse a sí mismo, con sus nuevas metas y sus nuevos valores, y así establecer la Forma del Mundo como espacio total del Trabajo. Luego Jünger concluye: «La existencia de un Tipo nuevo humano es un Capital que aún no ha sido reclamado. Ese tipo humano nuevo es la más afilada de las armas ofensivas, es el supremo medio de poder que está a disposición de la Forma del Trabajador» ${ }^{44}$. No es menor que Jünger se refiera al ser del Trabajador como Capital original y que vea ahí, como Capital, el supremo medio de poder al servicio de la Forma del Trabajador. Entonces el sentido esencial del Capital no viene, como piensa Schultz, de la consecuencia de englobar en un concepto teórico exhaustivo de inversión económica todos los recursos disponibles. Pero que ahora se trate de abarcar bajo este concepto económico un nuevo Tipo de Trabajador, uno tal que ha puesto su valor en el resultado de una inversión previa en capacidades, habilidades y destrezas, no quiere decir sino que sólo ahora puede hacerse eviden-

[40] Heidegger, M. Parmenides, Gesamtausgabe Band 52, Frankfurt am Main, 1992, pág. 127.

[41] Jünger, E. Op. Cit. Pág. 75 (Las cursivas son mías).

[42] Idem.

[43] Ibidem. Pág. 76.

[44] Idem. (Las cursivas son mías).

THÉMATA. Revista de Filosofía, Nº51 enero-junio (2015) pp.: 125-143 doi: 10.12795/themata.2015.i51.07 
te el principio de la voluntad de poder como Trabajo bajo la Forma del Capital humano. Es la economía la que reclama ese nuevo Tipo humano y lo hace suyo, por cuya dirección se hace incondicionado el poder que se lleva a cabo en el Mundo técnico por mor únicamente del aseguramiento de la voluntad de poder. En la medida que el Trabajador dispone de sí como Capital y, a su vez, dispone de todo como recurso capitalizable, las relaciones fácticas se transforman decisivamente al llevarlas a la organización total del Mundo como Trabajo.

Sólo ahora se deja ver el nuevo Tipo de Trabajador, cuya operatividad no significa tanto mano de obra o, en general, fuerza de trabajo, sino antes bien principio de dirección y planificación incondicionada. Nietzsche dice lo siguiente: «Cada vez es necesaria menos fuerza física: con inteligencia se hace que trabajen las maquinas, el hombre se vuelve más poderoso y más espiritual» ${ }^{45}$. El Trabajador, en ese sentido, despliega toda su voluntad operativa como Capital humano al movilizar el Mundo por medio de su más espiritual "recurso", el lenguaje, que como in-Formación, revela la voluntad de fijar el Caos siempre más extensamente y disolver toda imprecisión en una «construcción orgánica» ${ }^{46}$. En ese sentido «la Técnica es el dominio del lenguaje que está vigente en el espacio de Trabajo ${ }^{47}$. Por tanto, una correcta relación con la Técnica depende del grado en que la vida humana sea representante de la Forma del Trabajador. La esencia de la Técnica se vuelve evidente desde el lenguaje, en la conformación del Mundo y la vida a partir de una siempre creciente in-Formación. Así la in-Formación moviliza el Mundo, lo cual no quiere decir ciertamente que el Mundo esté en control de la opinión de la prensa o la publicidad, pues éstas son sólo una consecuencia. La in-Formación quiere decir el modo de conformar el Mundo en una Forma, en una Imagen, representable y disponible desde sí y para sí. El Trabajador pone ante sí la realidad, la representa, la in-Forma en su dominio. Pero lo real así representado es en cada caso recurso capitalizable, es decir, valor calculable y dispuesto a reproducirse incondicionadamente, con lo cual la voluntad de poder encuentra su más propio aseguramiento en el Capital como su propia esencia.

El Capital, ontologicamente pensado, designa la esencia misma de la voluntad de poder, su principio y orden. El Capital no designa primero la acumulación de dinero o de bienes para una futura inversión, sino antes bien el principio y el fin del espacio de Trabajo. Si efectivamente el Capital es el principio de la voluntad que se asegura a sí misma en la sobrecapacitación creciente de su capacidad y así llega a ser la nueva Forma del Trabajador, entonces de ninguna manera el Trabajador es el Tipo activo de la transvaloración de todos los valores. Más bien, el Capital humano cumple propiamente

[45] Nietzsche, F. Fragmentos póstumos IV, ed. cit., 2006, pág. 63.

[46] Jünger, E. Op. Cit. Pág. 115.

[47] Ibidem. Pág. 148.

THÉMATA. Revista de Filosofía, Nº51 enero-junio (2015) pp.: 125-143 doi: 10.12795/themata.2015.151.07 
la lógica de la valoración burguesa y más antigua aún, cuyo fin es el acrecentamiento de su ser a través de la sobrepotenciación de una subjetividad incondicionada y no la transfiguración de la vida a un mayor grado de claridad y fuerza, como Nietzsche dictaba.

Jünger reconoce que en la fase última del Nihilismo, es decir, en el fenómeno del completo derrumbe de los valores antiguos, ocurre precisamente un choque de fuerzas armadas que pretenden reivindicar sus derechos ${ }^{48}$. De estas fuerzas una ha alzado la nueva Forma del Trabajador. El Capital humano llega a ser el principio de la voluntad de poder, donde el poder es representado como Forma del incondicionado dominio del Mundo del Trabajo, pero bajo la apariencia de la superación del Nihilismo. El valor principal, el Capital, se eleva a un rango supremo de señorío, pero no superando los valores anteriores, sino cumpliéndolos. Su persistente validez acrecienta la devastación de la Tierra, acontecimiento enmascarado, en palabras de Luis Sáez Rueda, por una ficcionalización del Mundo ${ }^{49}$. El Capital humano es el que lleva a cabo los valores del burgués o, en términos más amplios, el que lleva el Nihilismo a su mayor extremo. Esto implicaría que el Nihilismo no es superado, sino, por el contrario, llega a su consumación, y de tal modo que en el vacío de las metas logra aparecer el empequeñecimiento del hombre como su opuesto y así surge la apariencia de un nuevo orden, pero no es más que la última Forma del Trabajador, cuyo Tipo cada vez se hace más dominante. Al elevarse el Capital humano desde la oposición entre el Capital y la fuerza de trabajo, el Trabajo cobra Forma total y sólo así el empequeñecimiento puede durar largo tiempo y permanecer en la apariencia de un sentido, pero no es más que la consumación del Nihilismo en la producción, administración y consumo de valores, con lo cual se asegura a sí misma la voluntad de poder en su capitalización incondicionada.

Pero tenemos que preguntar aún con mayor alcance, pues ¿no está ya de partida la Forma del Trabajador sometida a esta apariencia, a saber, a la apariencia de la superación del Nihilismo? Lo que da derecho a preguntar así es la advertencia que hace Heidegger al afirmar que es precisamente la interpretación del ser como valor lo que en primer término prohíbe toda superación a partir de la Metafísica del Trabajador. Pero, por otra parte, tal vez sea una más profunda comprensión del Trabajo lo que conlleve una transformación de la perspectiva del Nihilismo activo. Tal cuestión se suscita a raíz de que Heidegger haya visto en el Trabajo, a la luz de su sentido ontológico, el cumplimiento mismo del vínculo con el ser ${ }^{50}$. Ello implicaría pensar el Trabajo desde

[48] Jünger, E. Op. Cit. Pág. 74.

[49] Sáez Rueda, L. "Ficcionalización del mundo. Aportaciones para una crítica de patologías sociales” en Rev. Filosofía Univ. Costa Rica, XLV (115/116), Mayo-Diciembre 2007, pág. 59.

[50] Heidegger, M. Logik als die Frage nach dem Wesen der Sprache, Gesamtausgabe Band 38, Vittorio Klostermann, Frankfurt am Main, 1998, pág. 153ss.

THÉMATA. Revista de Filosofía, No51 enero-junio (2015) pp.: 125-143

doi: 10.12795/themata.2015.i51.07 


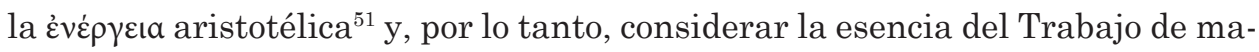
nera más original. Por ahora una pregunta es más urgente: en la Técnica como actividad racional de renovación capitalizadora del proceso de rendimiento y consumo, y en el constante asalto ejercido sobre todo lo ente reducido a valor, ¿no se asegura a sí misma la voluntad de poder volviendo sobre sí? ¿Es así como está destinado el eterno retorno de lo igual a consumar el Nihilismo?

[51] Para ello sería necesaria una confrontación con el libro $\Theta$ de la Metafísica de Aristóteles, y

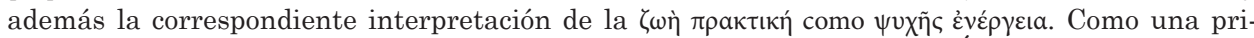
mera indicación hacia esto remito a De Bravo, C. [en línea] "Aristóteles, Ética a Nicómaco, libro II (1103a14-1109b29). Traducción fenomenológica con introducción y notas" en revista Ápeiron. Estudios de filosofía. http://www.apeironestudiosdefilosofia.com/\#!estudios-de-filosofia/mainPage. Págs. 382-412.

THÉMATA. Revista de Filosofía, Nº51 enero-junio (2015) pp.: 125-143 doi: 10.12795/themata.2015.i51.07 


\section{Referencias bibliográficas}

Cerezo, P. "La cuestión del Nihilismo. La confrontación Nietzsche/Heidegger" en Pensar la Nada. L. Sáez, J. de la Higuera y J. F. Zúñiga (Eds). Biblioteca Nueva Madrid, 2007.

De Bravo, C. [en línea] "Aristóteles, Ética a Nicómaco, libro II (1103a 14-1109b 29). Traducción fenomenológica con introducción y notas" en revista electrónica Apeiron. Estudios de filosofía. http://www.apeironestudiosdefilosofia.com/\#!estudios-de-filosofia/mainPage. [Consultado 13/10/2014].

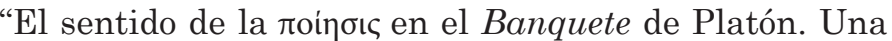
contribución al problema de la esencia de la técnica". Alpha, N 38, Julio, 2014.

Descartes, R. Discurso del Método, Biblioteca Edaf, 2005.

Foucault, M. Enfermedad mental y personalidad. Editorial Paidos, Barcelona, 1984.

Buenos Aires, 2007.

Nacimiento de la biopolítica, Fondo de cultura económica,

García de la Huerta, M. Crítica de la razón tecnocrática, Editorial Universitaria, Chile, 1990.

Heidegger, M. Nietzsche I, Ediciones Destino, Barcelona, 2000.

mann, Frankfurt am Main, 1992.

Parmenides, Gesamtausgabe Band 52, Vittorio Kloster-

Logik als die Frage nach dem Wesen der Sprache, Gesa-

mtausgabe Band 38, Vittorio Klostermann, Frankfurt am Main, 1998.

Vorträge und Aufsätze, Gesamtausgabe Band 7, Vittorio

Klostermann, 2000

Jünger, E. El Trabajador. Dominio y figura, Tusquets editores, Barcelona, 1990.

Jünger, E. "Sobre la Línea" en Acerca del nihilismo. Ediciones paidós I.C.E/U.A.B, 1994.

Löwith, K. "Heidegger, pensador de un tiempo indigente. Sobre la posición de la filosofía en el siglo XX", Fondo de cultura económica, México, 2006.

Martínez Marzoa, F. "La filosofía de «El Capital» de Marx", Taurus ediciones, 1983.

Marx K. El Capital, libro primero, crítica de la economía política, el proceso de producción de capital, Siglo veintiuno editores, 2008.

Nietzsche, F. Así habló Zaratustra, Alianza editorial, Madrid, 1996. Fragmentos póstumos III, Tecnos, Madrid, 2010. Fragmentos póstumos IV, Tecnos, Madrid, 2006. 
Queraltó, R. "Razón científica y razón técnica en el fin de la modernidad”, Anuario Filosófico, 1994 (27), pp. 683-697.

Sáez Rueda, L. "Ficcionalización del mundo. Aportaciones para una crítica de patologías sociales" en Rev. Filosofía Univ. Costa Rica, XLV (115/116), Mayo-Diciembre 2007, pp. 57-69.

Santos Herzeg, J. "Filosofía de mercado. El filósofo profesional como MINY-PYME" en Paralaje N², Dossier, 2011, pp. 45-63.

"Tiranía del Paper. Imposición institucional de un tipo discursivo" en Revista chilena de literatura, Noviembre, N82, 2012a, pp. 197-217.

"30 años de filosofía-FONDECYT. Construcción de una elite e instalación de una patrón investigativo" en $\operatorname{La}$ Cañada $\mathrm{N}^{\circ} 3,2012 \mathrm{~b}$, pp. 76-116.

"El trabajo filosófico en la época de la profesionalización" en La presencia de la filosofía en la Universidad, Porto Alegre, 2003, págs. 145-159.

Schultz, Th. "Investment in man: an economist view", The Social Service Review. Vol. XXXIII, Nº. 2. 1959. 
